\title{
Decision Making Tools for Optimal Alternative Energy for Industries
}

\author{
Prateep Rattanapunt ${ }^{1}$ and Ratthasak Prommas*2 \\ ${ }^{1}$ Rattanakosin College for Sustainable Energy and Environment (RCSEE), \\ Rajamangala University of Technology Rattanakosin. 96 moo 3 Puthamonthon Sai 5, \\ Salaya,Puthamonthon,Nakhon Pathom,73170,Thailand. \\ Prateep.r@rmutr.ac.th \\ ${ }^{* 2}$ Department of Mechanical Engineering, Faculty of Engineering, Rajamangala University of Technology \\ Rattanakosin, 96 moo 3 Puthamonthon Sai 5, Salaya,Puthamonthon,Nakhon Pathom, 73170, Thailand. \\ ratthasak.pro@rmutr.ac.th
}

\begin{abstract}
The objective of this study was to analyse the use of biofuels to replace fossil fuels through mathematical analysis in creating an artificial intelligence (AI) programme as the tool for consideration and decision of fuel replacement from non-renewable. This study emphasises the potential of fuel replacement from non-renewable energy to alternative energy. The target group for this study included dyeing factories using boilers as the main equipment for production. While the developed Matlab AI programme was tested and helped dyeing factories to decide the selection of energy. The programme led to the process of artificial neural networks simulating the human brain performing mathematical analysis, which is the process of model neural network creation. The results of the study about the breakeven point ranking programme found that, the break-even point for coal was distant from the break-even point for palm shell fuel by 23 points, showing that palm shell fuel was more valuable. In the comparison between bunker oil and other types of fuels, it was found that the break-even point for bunker oil was ranked No.26, whereas the break-even point for palm shell fuel was ranked at No.1. As well, the comparison of natural gas with other types of fuels found that the break-even point for natural gas was ranked at No.17, whereas the break-even point for palm shell fuel was ranked at No.1; these two types of fuels were separated from each other by 16 points.
\end{abstract}

Key words - Alternative energy, Artificial intelligence, Energy analysis

\section{INTRODUCTION}

The global demand for energy has increased unceasingly since 2013 [1] as a result of better living standards in emerging economies around the world, including in China, India and countries in the Middle East. The economies in these and other nations have rapidly expanded, with such development and expansion having perpetually caused higher demand for energy. Further, the proportion of use for fossil fuels have been decreased rapidly, while the demand for renewable energy and alternative energy has increased [2]. China is considered the largest importer and consumer of gasoline, whereas the United States of America and various other nations store tremendous amounts of fossil fuels necessary for use as energy from domestic resources, mainly because the populations in these nations require and use huge amounts of energy. Therefore, the effective use of energy in the present era is truly significant [3]. However, capability regarding the effective use of energy has not been fully applied, with every country all over the world required to search for guidelines in using energy with the most effectiveness to minimise the use of fossil energy and turn to using alternative and renewable energy sources including sunshine, wind, and water, as well as leftover agricultural products and other environmentally friendly means in order to accomplish the most effectiveness and efficiency.

Thailand emphasises the importance and execution of energy conservation by supporting both the manufacture and use of domestic renewable energy as well as the lowering of energy resource importing, which also causes monetary loss and affects the country's energy security. In addition, energy prices have a tendency to increase and fluctuate. This is because the continuing reduction of fossil fuel margins has an effect on price fluctuations to be more severe. Above and beyond the non-existence of good management, it also interrupts the country's economy [4].Thailand is an agricultural-based country with good soil for fruitful planting. Thus, there are a lot of resources from leftover agricultural products such as palm shells, coconut shells, rice hulls, corncobs, etc. These leftover products could be supplied to produce environment-friendly heat fuel for industrial applications at lower costs than fossil fuel. This would lead to the reduction of energy expenditure in the industry required for heat systems. All mentioned advantages point to biofuel as the optimal fuel, particularly since it could sustainably replace fossil energy used in large-scaled industrial plants, such as those factories that require heat for their manufacturing process. An alternative method for decision-making and development is by applying an AI technique to reach the intended break-even point of0 values to obtain essential information. From the experiment of the sample group, which is dyeing factories, the results showed achievement as expected. It was found that palm shell fuel could achieve a No.1 break-even point close to 0, conveying that any 
factory using palm shell as fuel for boilers would attain a good break-even point. Furthermore, comparing coal, bunker oil and natural gas found that bunker oil had break-even point the farthest from 0 values.

From this study, it was found that the advantage of alternative energy analysis is to have the Fuel Analysis Programme as an alternative for selecting optimal energy to be used in industrial factories. The programme could perform accurate calculations for the comparison of coal, bunker oil, natural gas and biofuel, consequently encouraging factories to effectively decide to use biofuel.
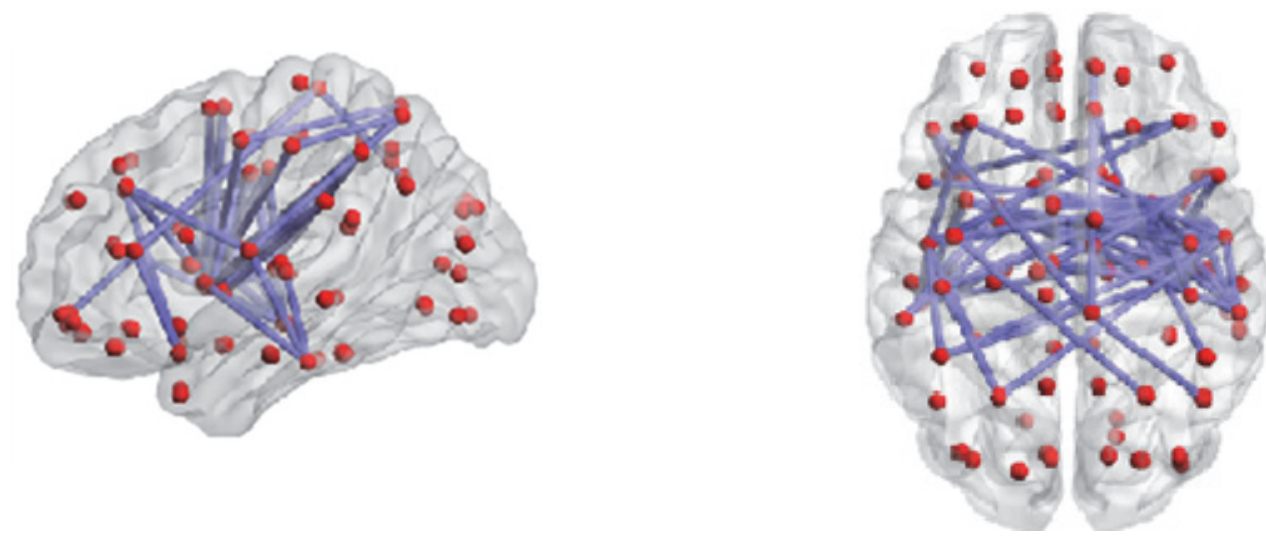

Fig. 1. How artificial neural networks work

Fig. 1. Illustrates how artificial neural networks work through the use of computer programme to simulate how the human brain functions. It comprises mathematical modelling with the function of information processing. Inside a computer, neurons are similarly comprised of input nodes and output nodes, with each input node simulated to have a weight as the determinant of input weight. Each unit of neuron has a threshold value to determine the value of total weight for input to capably fire and trigger output to other neurons [6]. When connecting all neuron units to work in conjunction, logically, this operation is similar to the chemical reactions that occur in the human brain. The programme displays the results using numbers.

\section{Methodology}

Preparation Procedures:

1) Study involving documents and researches: Starting from applying breadth-first search to study information in the direction set to search each layer of the tree structure, beginning from root node; then applying depth-first search to study and research through the direction of the tree structure, starting from root node at the top, then exploring to the deepest node. Furthermore, blind search is search from one node to another node based on direction, as the search determinant is also applied.

2) Contact of organisations and collection of necessary data: The following steps were carried out coordinating with dyeing factories to collect required data about steam boilers and non-renewable fuel consumption, followed by selecting dyeing factories located in the perimeter zone as the sample group. After that, collecting data related to potential values of many types of fuels was done, followed by analysing all data collected and measuring values from equations. The calorific value is the amount of heat produced by the combustion of a fuel obtained during fuel combustion by cooling such complete combustion to reach the atmosphere temperature level, its unit is $\mathrm{kJ} / \mathrm{kg}$ or $\mathrm{kJ} / \mathrm{m}^{3}$ and its values are classified into High Heat Value (HHV) and Low Heat Value (LHV). The calorific value including heat is called steam condensation releasing from smokestack. Low Heat Value (LHV) is calculated using the following equations:

$$
\begin{aligned}
& \mathrm{LHV}=\mathrm{HHV}-\mathrm{mwhfg} \\
& \mathrm{LHV}=\mathrm{HHV}-9 \mathrm{mH}_{2} \mathrm{hfg}
\end{aligned}
$$

Where as $\quad \mathrm{mw} \quad$ is the steam mass produced by combustion per 1 unit of fuel

$\mathrm{mH}_{2}$ is the mass of hydrogen atom in 1 kilogram of fuel obtained from the analysis of fuel components in the laboratory in order to know $\% \mathrm{C}, \% \mathrm{H}, \% \mathrm{O}, \% \mathrm{~N}, \% \mathrm{~S}$ and $\%$ Ashes

Number 9 is the ratio for molar mass of water per hydrogen

hfg is the hidden calorific value of steam evaporation or condensation at partial pressure in a substance produced by combustion 
All combustion is classified into the 3 following types:

1) Complete Combustion:

-Balanced chemical equation resulting in the most effective combustion:

$\mathrm{C}+\mathrm{O}_{2}=\mathrm{CO}_{2}+\mathrm{HEAT}$

$2 \mathrm{H}_{2}+\mathrm{O}_{2}=2 \mathrm{H}_{2} \mathrm{O}+$ HEAT

$\mathrm{S}+\mathrm{O}_{2}=\mathrm{SO}_{2}+\mathrm{HEAT}$

Where $\mathrm{CO}_{2} \quad$ Carbon Dioxide

$2 \mathrm{H}_{2} \mathrm{O}$ Complete combustion is the combustion of substances having fuel produced by water and carbon dioxide as the product substance:

$\mathrm{SO}_{2} \quad$ Sulphur dioxide

S Solid

2) Incomplete combustion due to excess air: The equation underneath the figure demonstrates that, after the reaction, its equation is $\mathrm{CO}_{2}+2 \mathrm{H}_{2} \mathrm{O}+0.4 \mathrm{O}_{2}+\mathrm{N}_{2}+$ ppm CO $+\mathrm{ppm} \mathrm{H}_{2}+\mathrm{NOX}$, with gas non-existent in the balanced chemical equation such as $0.4 \mathrm{O}_{2}$, ppm CO, ppm $\mathrm{H}_{2}$, NOX, causing energy loss and subsequently resulting in the reduction of energy output.

3) Incomplete combustion due to excess fuel consumption: The equation underneath the figure demonstrates that its equation after the reaction is $0.6 \mathrm{CO}_{2}+1.6 \mathrm{H}_{2} \mathrm{O}+0.4 \mathrm{CO}+0.4 \mathrm{H}_{2}$, with gas non-existent in the balanced chemical equation such as $0.4 \mathrm{CO}, 0.4 \mathrm{H}_{2}$, causing energy loss and the subsequent reduction of energy output.

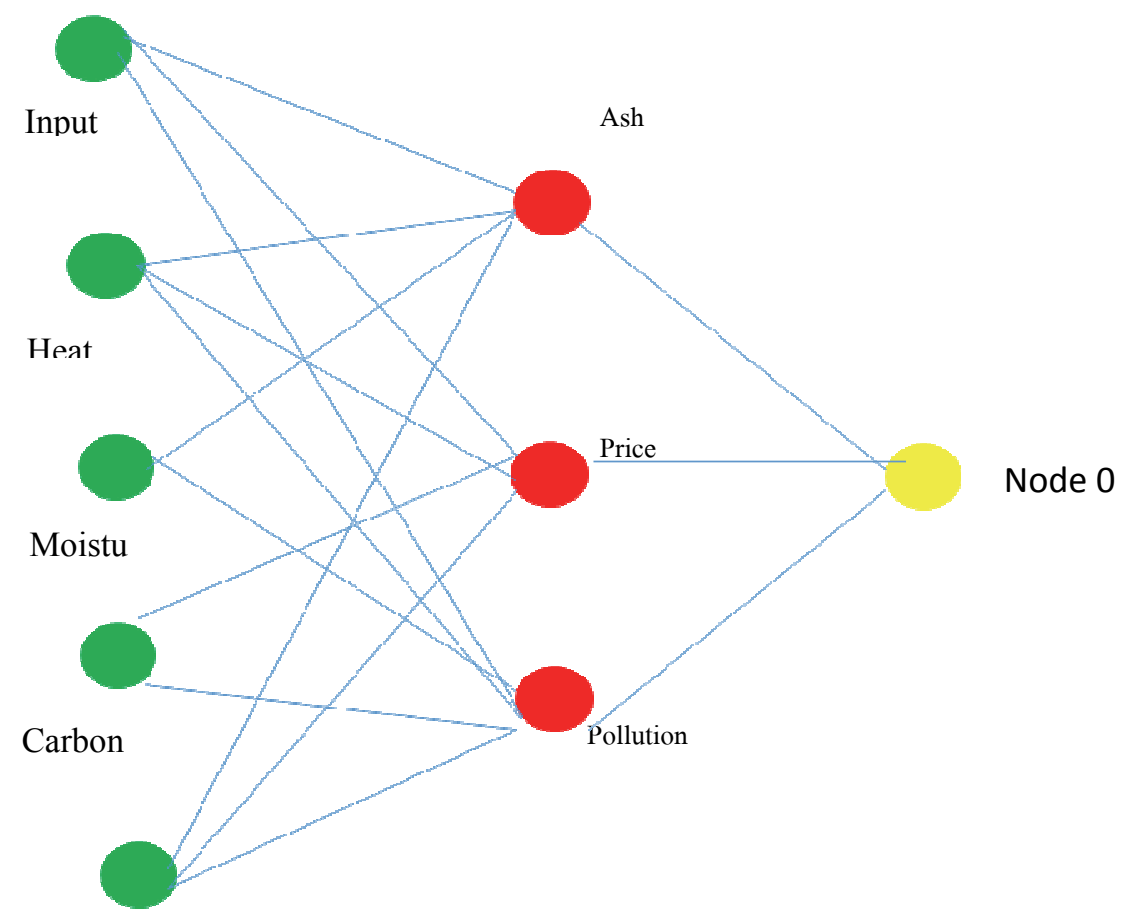

Volatile

Fig. 2. Artificial neural network structure of the loaded file 
Fig. 2. Illustrates their typical neural network structure of the loaded file, which shows the weight of connections between each node. Its structure is comprised of3 layers as follows:

The $1^{\text {st }}$ Layer is called the "Input layer". All nodes are green, which are loads of attributes and comprised of input, heat value, moisture, fixed carbon and volatile matter;

The $2^{\text {nd }}$ Layer is called the "Hidden layer". All nodes are red, which are comprised of attributes divided into 3 nodes such as ashes, price and pollution value;

The $3^{\text {rd }}$ Layer is called the "Output layer". All nodes are yellow and show values.

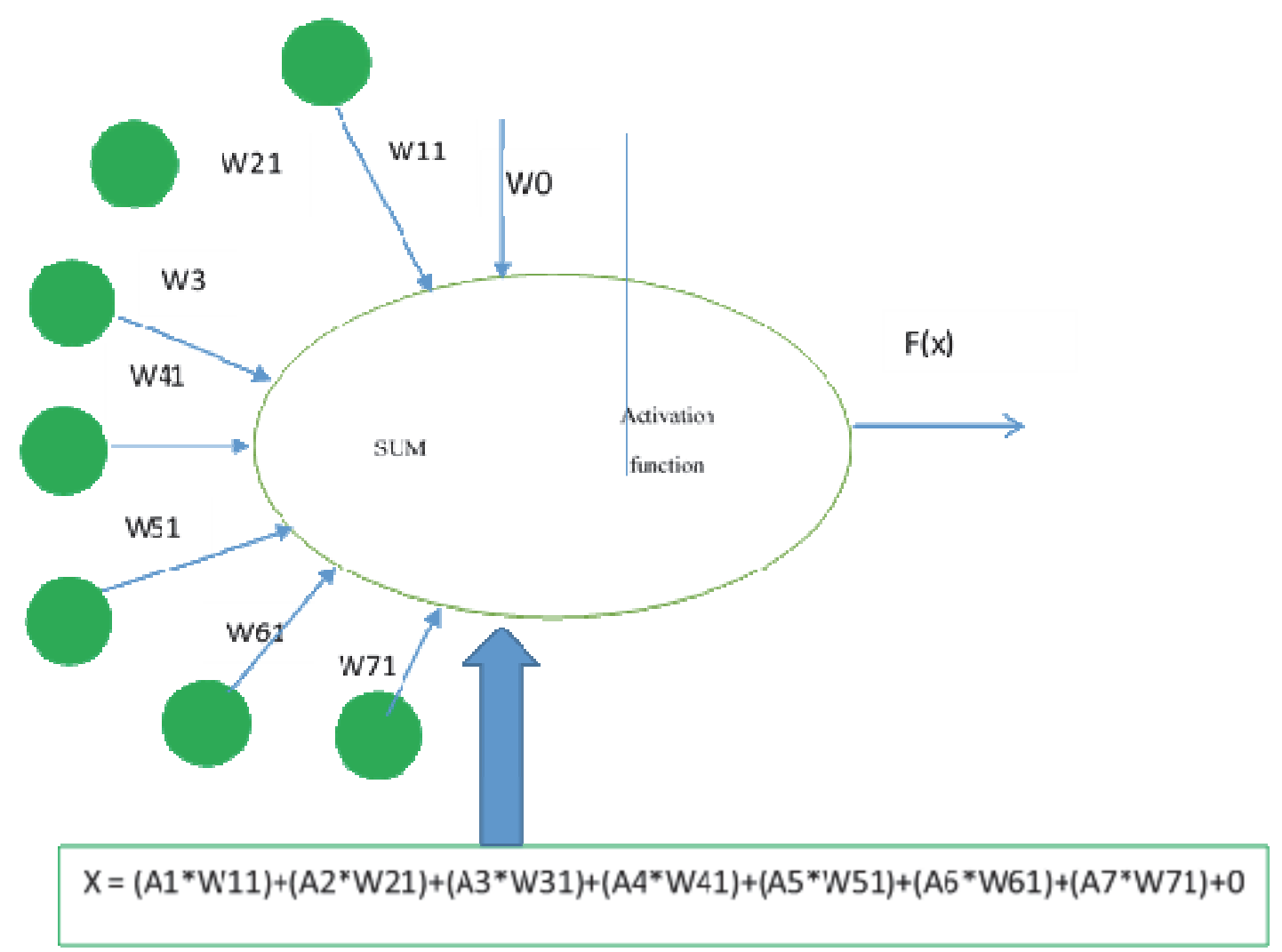

Fig. 3. Internal calculation of each node in the artificial neural networks

Fig. 3. is divided into 2 sub-processes as follows:

1) Sum calculation: In this stage, node values are multiplied by a weight in each connection and then summed up as the final value;

2) Output calculation by applying activation function: The function applied is the sigmoid function, which is a mathematical function having a characteristic "S"-shaped curve and its function as $1 /(1+\mathrm{e}-\mathrm{x})$;

3) Creation of tools for data research and analysis: Collecting and analysing data obtained from the study and research; Programming the development of the Artificial Intelligence (AI) for the selection of fuel consumption using the theory of genetic algorithm, as shown in the flow chart in Fig 2. 

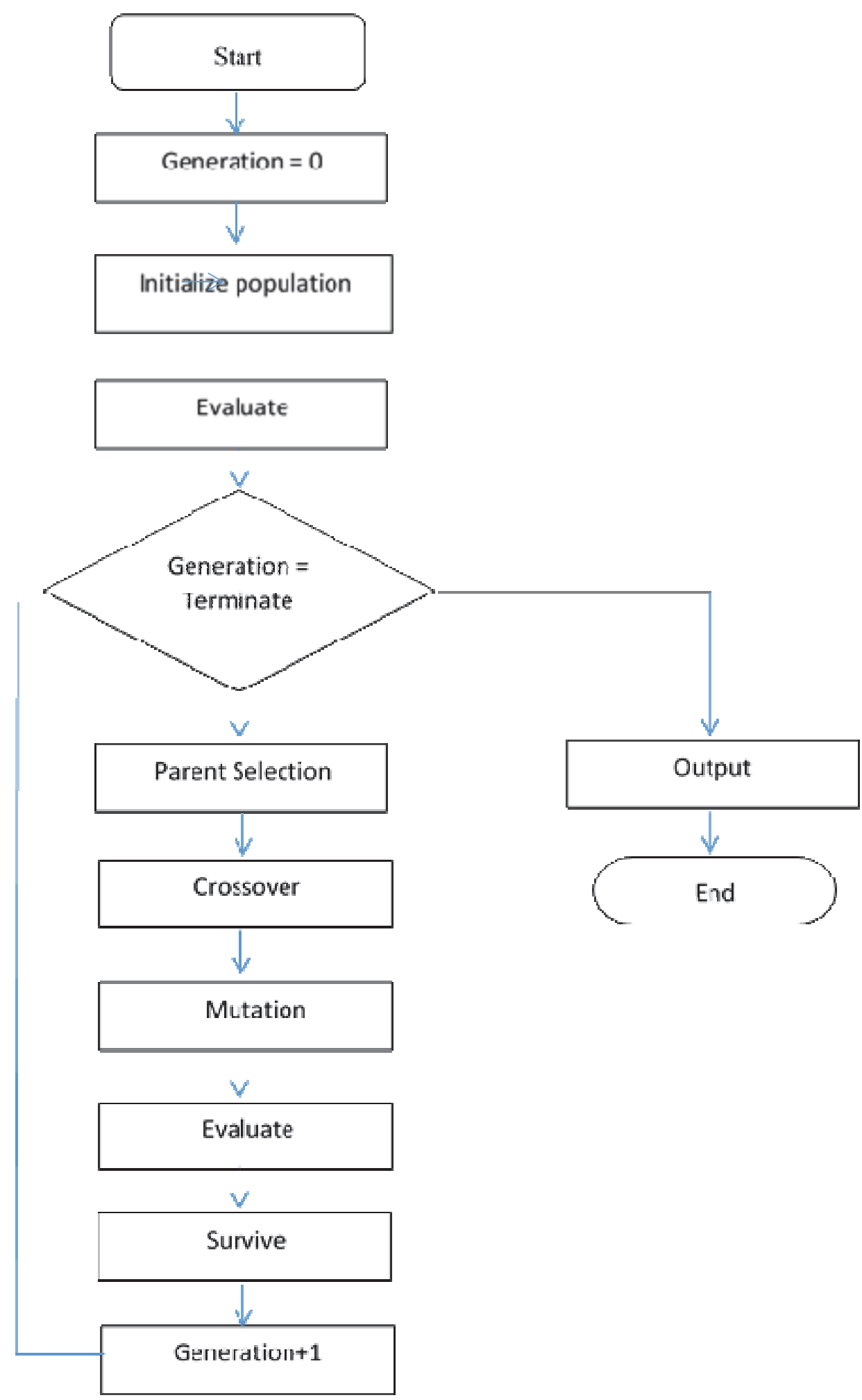

Fig. 4. Calculation Steps

4) Programme test using data analysed and obtained from site visits at dyeing factories located in the perimeter zone: Interviewing for data collection and applying fuel data collected from industrial plants consuming non-renewable fuels such as coal as the main fuel for steam boilers. Additionally, the interviews focused on the processes of fuel selection, data collection and analysis for application in the programme test.

5) Application of AI programme by using Matlab in code writing for input and target data, followed by creating a train programme FNN to analyse and compare data relating to each type of biofuel. In this section, performance analyses a number valued between data and output to reach 0 the most. 


\section{Analysis Tools and Methods}

1) For the FNN programme, which was created using Matlab, it shows 3 components of functions on the screen. The first component is a train programme, which imports data and analyses input and target detain excel file format. It is a part of the programme training to receive data similar to the human brain. The second component is called Find Each Worthiness, which inputs data for single-data analysis. The last component is called find best worthiness (File), which analyses data of best fuel acquisition by ranking as numbers in order to know the best fuel value analysed by the programme, as shown in Figure6.

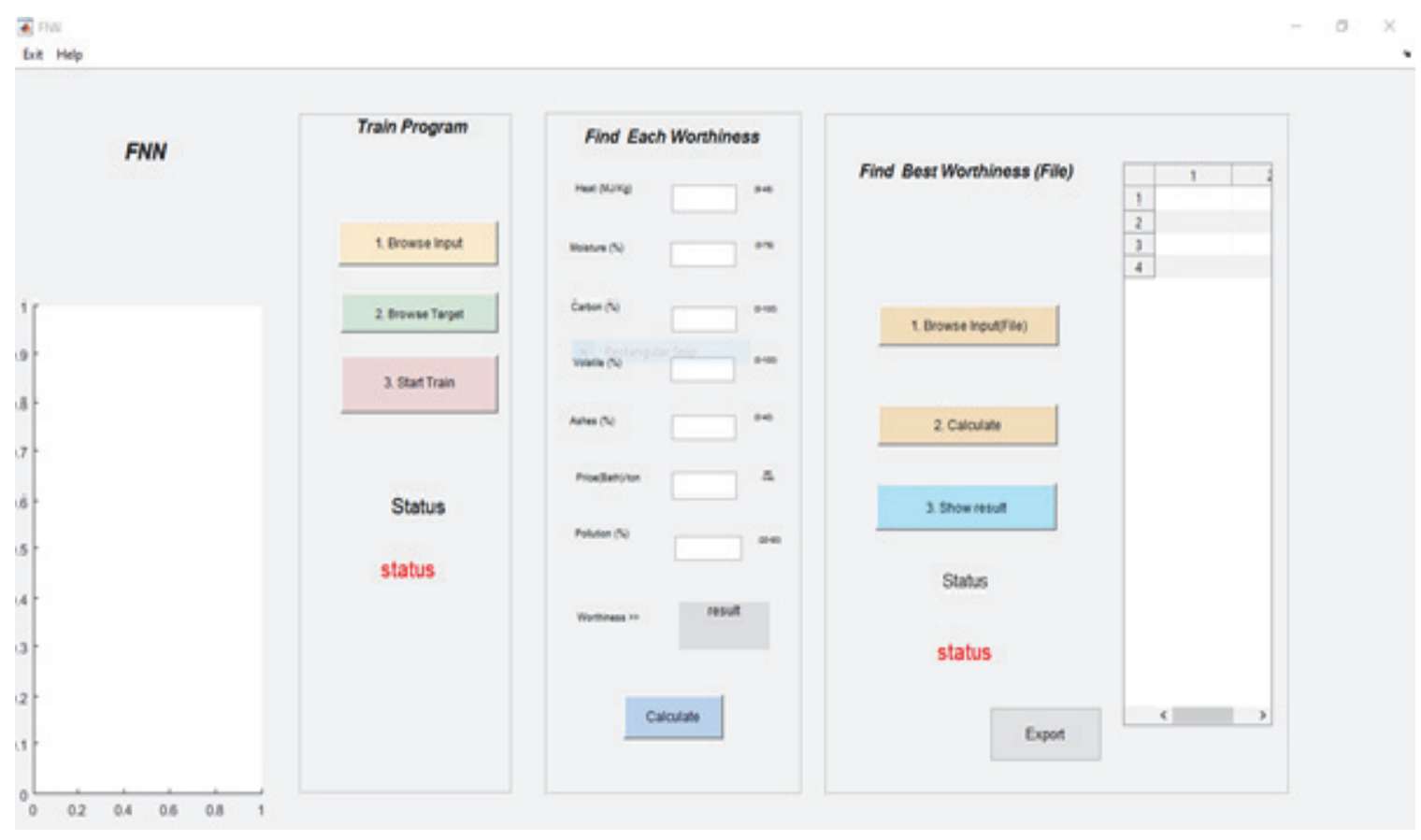

Fig. 6. Window showing all three components of the programme

2) As shown in Figure7, all data for the 3 components were input and hidden, which played a role in data connection, data division selection of bayesian regularisation variables by determining the value, and performance specified mean square error to reach " 0 " the most. The programme could be input by a maximum 1,000 set of data to train the brain. all data was collected from 10 dyeing factories in the central region, which tested fossil fuel consumption. Additionally, the data set was managed into 7 nodes containing calorific value $(\mathrm{MJ} / \mathrm{Kg})$, humidity (\%), fixed carbon (\%), volatile matter (\%), Ashes (\%), price (Baht/ton) and air pollution (\%).

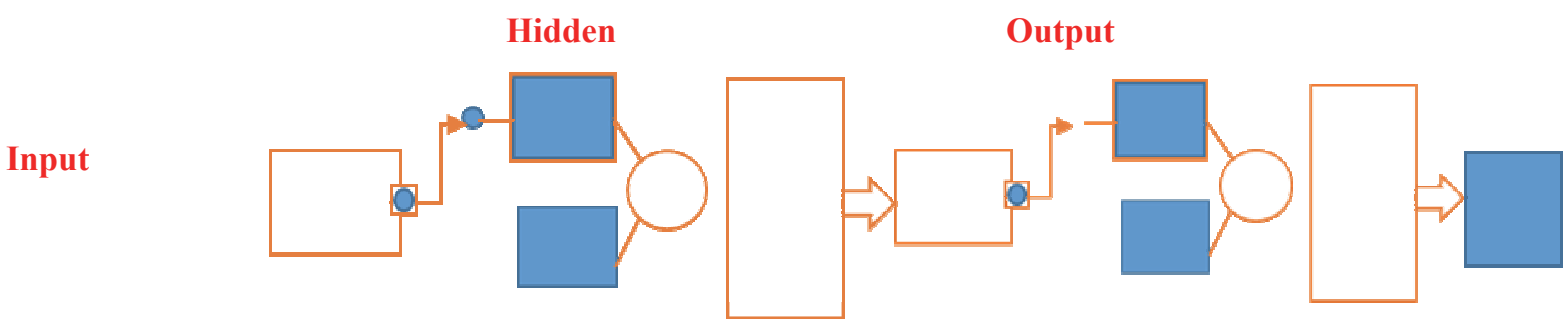

Fig. 7. Input, Hidden and Output of the programme

3) The target was set to determine the value of the train programme on neural networks, while data was processed by allowing performance to achieve " 0 " the most to simulate the functions of human neural networks. It is the train programme for supervised learning, which is learning with answer checking to enable artificial neural networks to adjust. A set of data applied for training artificial neural networks has answers for checking whether or not the neural networks respond correctly. If the answer is incorrect, a neural network will adjust itself for a better answer. The train programme FNN is the creation of a learning relationship for the best results, which is the closest to actuality. The programme could produce no less than 1,000 sets of data for data accuracy and acceptance. 


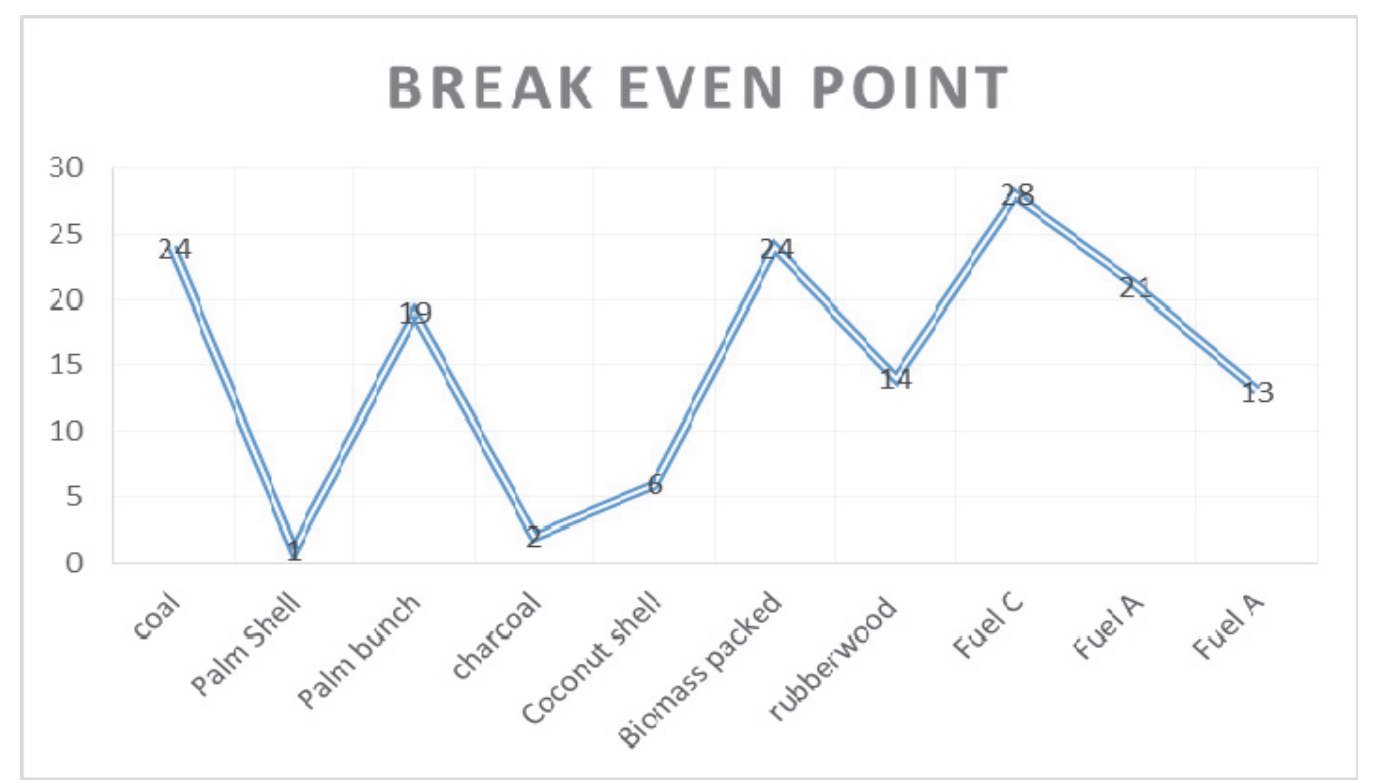

Fig. 8. shows the break-even point for coal fuel consumption compared to other types of fuels in industrial plants through the use of the FNN Programme.

From Fig. 8. y-axis was set as the break-even point for fuel and x-axis was set as the fuel consumed in textile manufacturing plants. The data was tested with the FNN programme and the results showed that the $2^{\text {nd }}$ plant consuming palm shell fuel as the fuel for steam boiler achieved the No. 1 break-even point, which was close to 0 according to the programme test. Meanwhile, the coal fuel ranked No. 24 for break-even point. In case of the programme test for bunker oil (Grade $\mathrm{C}$ ), the 8th plant was found to have its break-even point the most distant from0, meaning that the break-even point of bunker oil (Grade C) was lower than palm shell fuel when comparing the calculations between many types of fuel.

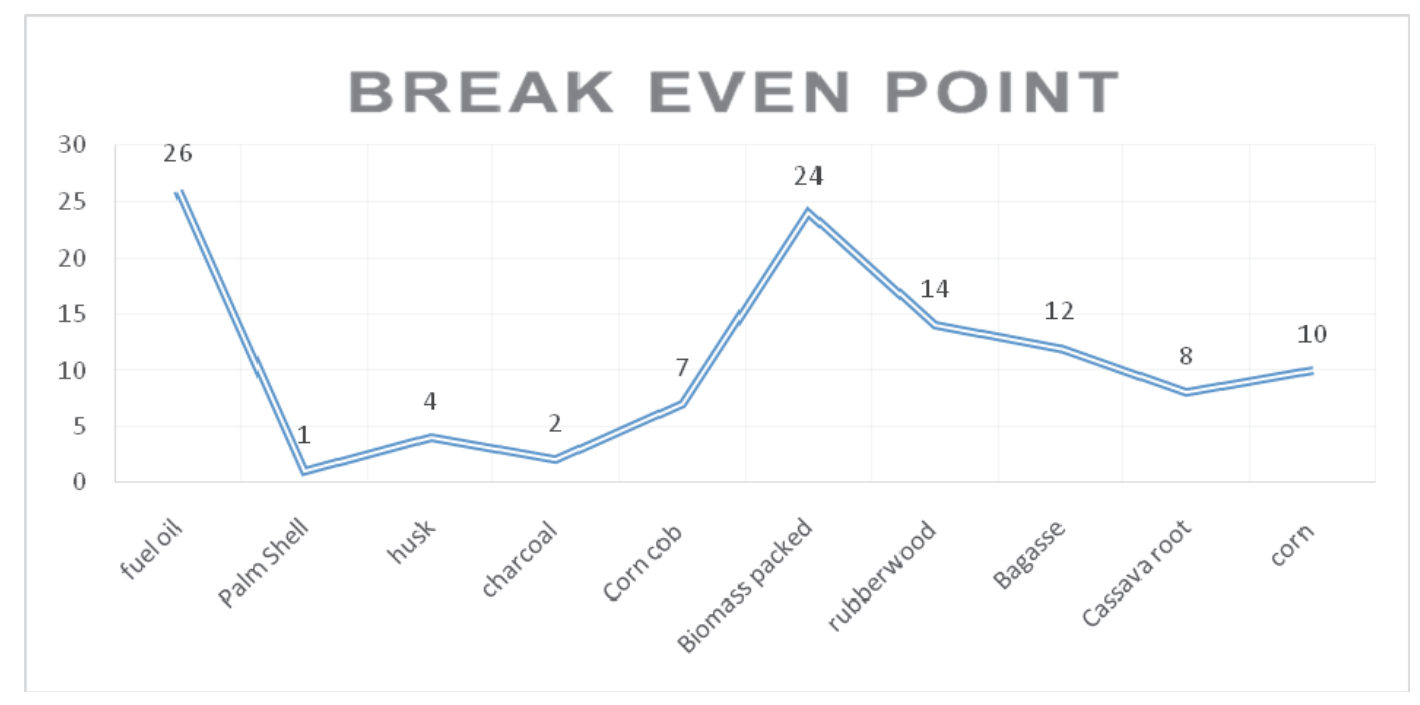

Fig. 9. shows the break-even point for bunker oil consumption compared to other types of fuels in industrial plants through the use of the FNN Programme.

Fig. 9. Illustrates the relationship between bunker oil and other types of fuels by using the test of FNN programme. Artificial neural networks simulate the human brain through mathematical analysis. It was clearly perceived that the bunker oil was distant from 0 by being ranked at No.17, whereas palm shell fuel was ranked at No. 1 with its value the closest to 0 . The gap between them was 16 ranks, which obviously explained that any value close to0 shall have the highest break-even point. If the ERROR value is close to0, it means the least error value. 


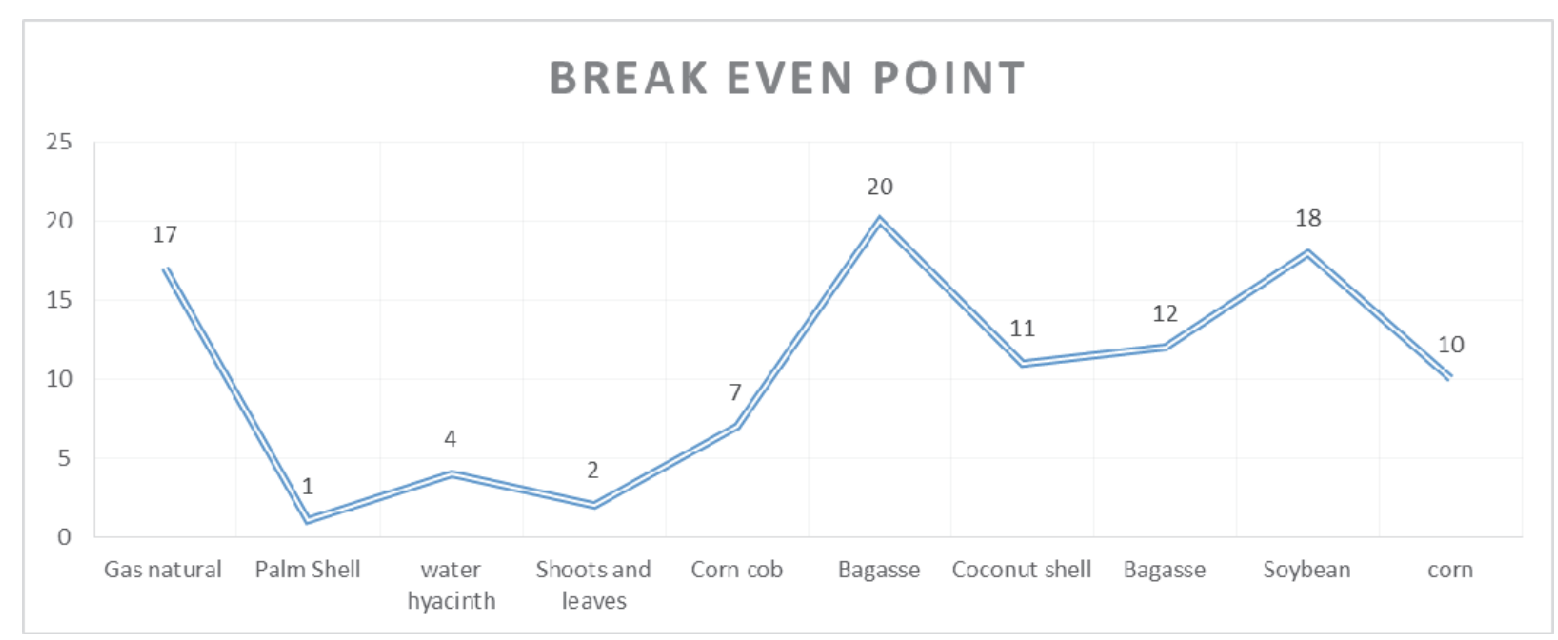

Fig. 10. Displays the break-even point for general gas fuel consumption compared to other types of fuels in industrial plants through the use of the FNN Programme.

Fig. 10. Illustrates the relationship between bunker oil and general gas fuel by using the test of FNN Programme. Artificial neural networks simulate the human brain through mathematical analysis. It was clearly seen that bunker oil was far from 0 by being ranked at No.26, whereas palm shell fuel was ranked at No. 1 with its value the closest to 0 . Both were separated from each other by 25 ranks, which clearly explains that any value close to0 shall have the highest break-even point. If the ERROR value is close to 0 , it means the least error value.

\section{Conclusions}

The artificial neural network model simulates by setting a weight for each input as the weight determinant. each unit of neuron has a threshold value to determine the value of input's total weight to capably fire and trigger output to other neurons. Each unit of neuron has a threshold value to determine the value of an input's total weight, then fire and trigger to output. The required data is obtained by setting the target of a breakeven point to reach0. The test of sample textile plants could be achieved for their results as forecast. It was found that palm shell could attain the No. 1 break-even point when comparing all 3 types of main fuels, meaning that the plant selecting palm shell as fuel for steam boilers would enjoy cost effectiveness. When comparing the various types of fuels consumed by industrial plants, it was found that bunker oil was remote from 0values.

The analysis of main fuels used in the programme test enabled the realisation of the external environment problems and all 7 nodes of factors to be calculated were calorific value (MJ/kg), humidity (\%), fixed carbon (\%), volatile matter (\%), ashes (\%), price (Baht/ton) and air pollution (\%). In addition, natural gas was also found to have a problem concerning thorough usability because the transportation system requires extension of the pipes, affecting rather high expenditure. The fuel itself was also found to be a transportation problem, which involves trucks used and driven for long distances. The problem of truck inadequacy potentially occurs if there is a critical case. Further, coal is required to be imported from overseas, causing many problems such as transportation, financial leakage to foreign countries and pollution.

The advantage of this alternative fuel analysis is the acquisition of a fuel analysis programme, which could be an alternative for industrial plants to select fuel for consumption. The calculation programme is also accurate for comparison. When comparing coal, bunker oil, natural gas and biofuel, the results enable plants to easily and conveniently select the most appropriate biofuel for their desired consumption needs.

\section{Acknowledgements}

This research was completed satisfactorily and successfully with assistance from various sources. The author highly appreciates the support and assistance of Rattanakosin College for Sustainable Energy and Environment (RCSEE), Rajamangala University of Technology Rattanakosinin facilitatingthe utilisation of the MatLab for AI development.

\section{References}

[1] Z. Y. Lai, H. B. Chua, S. M. Goh. Malaysia. Influence of process parameters on the strength of oil palm kernel shell pellets (Pages 1448-1456) (2013)

[2] U. Johnson Alengaram, Hilmi Mahmud, Mohd Zamin Jumaat:Malaysia, Enhancement and prediction of modulus of elasticity of palm kernel shell concrete (Pages 2143-2148) (2011)

[3] Muhammad 'Azim Jamaluddin, Microwave-assisted pyrolysis of palm kernel shell: Optimization using response surface methodology (RSM) (Pages 357-365) (2013)

[4] Faisal Abnisa, W.M.A. Wan Daud, J.N. Sahu, Optimization and characterization studies on bio-oil production from palm shell by pyrolysis using response surface methodology. (Pages 3604-3616) (2011)

[5] M.R. Wu, D.L. Schott, G. Lodewijks, Physical properties of solid biomass (Pages 2093-2105) (2011) 
[6] F.A. Olutoge, Nigeria: INVESTIGATIONS ON SAWDUST AND PALM KERNEL SHELLS AS AGGREGATE REPLACEMENT (Pages 1819-6608)(2010)

[7] Abechi E.S, Gimba C.E, Uzairu A, Kagbu J.A., Nigeria Kinetics of adsorption of methylene blue onto activated carbon prepared from palm kernel shell (Pages 154-164) (2011)

[8] Faisal Abnisa, W.M.A. Wan Daud, W.N.W. Husin, J.N. Sahu, Utilization possibilities of palm shell as a source of biomass energy in Malaysia by producing bio-oil in pyrolysis process (Pages 3604-3616) (2011)

[9] Rusila Zamani Abd Rashid, Hamzah Mohd. Salleh, Mohd Hanafi Ani, Nurul Azhani Yunus, Tomohiro Akiyama, Hadi Purwanto Reduction of low grade iron ore pellet using palm kernel shell [49] (Pages 617-623) (2014)

[10] Arash Arami-Niy, Wan Mohd Ashri Wan Daud, Farouq S. Mjalli , Faisal Abnisa,Mohammad, Saleh Shafeeyan, Production of microporous palm shell based activated carbon for methane adsorption: Modeling and optimization using response surface methodology. (Pages 776-784) (2012)

[11] Kellie W.Price,The use of imaging technology in introductory programming courses for computer science majors. (2013)

[12] Wojciech Grega,Integration control, centralized heat and power from renewable sources that are most desired compensation. The main objective of this research. (2012)

[13] Caixia Zhanga, Qihui Denga, Data processing and analysis, electron diffraction. By Visual Basic (Pages 2134-2137)(2011)

[14] Jiang Xiao, Assessing the sustainable competitiveness of the textile industry from AHP analysis capabilities in all three aspects of sustainable competitive textile industry in China. (Pages 49-68) (2012)

[15] Leonel JR Nunes and João, CO Matias,the application of biomass for energy production in the textile industry in Portugal. (Pages 336341) (2013)

[16] Dong-xiao Niu, Mian Xing, Ya-nan Wei, Jian-qing Li, Analysis and application systems, environmental impact assessment, biomass to produce electricity from the TOPSIS. (Pages 114-117) (2010)

[17] Wang Li-ping, Empirical studies ladder textile industry development trends. (Pages 54-59) (2009)

[18] Li Chuang, Research on the international competitiveness of China's textile industry in the EUmarket. (Pages 1-4 ) (2008)

[19] Yang Fan, The research on a comparison of the textile industry in technological innovation among countries. (Pages 390-394) (2010)

[20] FR Pazheri, Bagasse saving and emission reduction in energy co-generation by sugar mills and solar. (Pages 407-410) (2012)

[21] Dariush Semnani and MortezaVadood, In a previous study, the Board of yarn (ASTM) was analysed using image analysis and artificial neural networks. (2012)

[22] A. Nottrott, J. Kleissl, and B. Washom, Presented linear programming (LP) routine was implemented to model optimal energy storage dispatch schedules for peak net load management and demand charge minimization in a grid-connected, combined photovoltaicbattery storage system (PV+ system). (2013)

[23] Chaofeng Pan, Long Chen, Liao Chen, Chen Huang and Meizhi Xie, Learning focused on a vehicular system powered by two energy storage devices: battery and ultra-capacitor. (2013) 